\title{
Xanthine Dehydrogenase Inhibition Stimulates Growth and Development of Human Brain Derived Cells
}

\author{
K. E. Danielyan*, S. G. Chailyan \\ H. Buniatian Institute of Biochemistry, NAS RA, Paruyr Sevak Str, Yerevan, Armenia \\ *Corresponding author: danchrist743@yahoo.com
}

Received December 28, 2012; Revised August 29, 2013; Accepted September 01, 2013

\begin{abstract}
Background: Reactive Oxygen Species (ROS) play a critical role in development of number pathologies. Xanthine Oxidase (XO) as well as the Xanthine Dehydrogenase (XDH) are two enzymes responsible for the last steps of purine catabolism, hydroxylation of a wide variety pyrimidines, and the initiation of ROS synthesis. In our current experiments we have analyzed whether exogenously added allopurinol, not only the inhibitor of $\mathrm{XO}$ but also XDH, is capable for in vitro human brain derived cells growth, development and proliferation. Methods: We have used described by Mark Mattson's neuronal cell culturing technique to seed and keep cells in vitro over 12 days. The death of the cells was visualized by the staining with Trypan Blue. Pixcavator and Image Tool programs served for the calculation of the cells' number and size. Results: In comparison with the control group exogenously added xanthine as well as $\mathrm{NAD}^{+}$or addition of $\mathrm{NAD}^{+}$along with xanthine didn't play any critical role. Only the group, treated with $\mathrm{NAD}^{+}$, xanthine and allopurinol promoted elevation of the cells' number in the statistically significant way on the day $12^{\text {th }}$. Number of the death cells in comparison with the control groups in the cells groups treated with the xanthine, $\mathrm{NAD}^{+}$, as well as allopurinol was less, whereas in the $\mathrm{NAD}^{+}$and xanthine treated group this number was higher than in the control group. Conclusion: We have concluded, that treatment with the low concentration of allopurinol, will guarantee the survival of the cells, decrease the number of the death cells and promote the proliferative processes. These conclusions are similar for allopurinol treatment in condition of exogenously stimulated activity of $\mathrm{XO} / \mathrm{XDH}$ as well as endogenously stimulated activity of these enzymes.
\end{abstract}

\section{Keywords: Xanthine Oxidase, Xanthine Dehydrogenase, human brain derived cells, cell culture, allopurinol}

Cite This Article: K.E. Danielyan, and S.G. Chailyan, "Xanthine Dehydrogenase Inhibition Stimulates Growth and Development of Human Brain Derived Cells." American Journal of Medical and Biological Research 1, no. 4 (2013): 95-98. doi: 10.12691/ajmbr-1-4-2.

\section{Introduction}

It is very well demonstrated experimentally and proved practically that Reactive Oxygen Species (ROS) play a critical role in the pathological processes [2,9].

Taking into the consideration that around $20 \%$ of utilized oxygen distributes the brain it becomes clear how susceptible might be brain to the formation of ROS. The central nervous system requires a high-energy supply due to its intense ATP-consuming processes. Thus, abnormal cellular energy metabolism may impair neuronal function and plasticity. Under normal conditions, mitochondria are the major source of ROS, which are produced in the complexes of the electron transport chain [3]. Ichikava M. demonstrated subcellular mitochondrial localization of Xanthine Oxidase (XO) in rat hepatocytes by the utility of high-resolution immunoelectron microscopicy along with the biochemical analysis [7].

$\mathrm{XO}$ as well as the Xanthine Dehydrogenase (XDH) are two enzymes responsible for the last steps of purines metabolism, hydroxylation of a wide variety pyrimidines.

It is clear from the literature data that Xanthine Oxido Reductase (XOR) is the enzyme, which is able to function as an oxidase as well as a dehydrogenase. The main condition for the functioning XOR as a dehydrogenase is the presence in the media $\mathrm{NAD}^{+}$[6]. However, it is clear from the literature that the combination of XO and NADH is toxic to cultures of cerebral granule neurons [1]. The same authors indicate that the toxicity is mediated by the formation of superoxide and hydrogen peroxide because the addition of the catalase or superoxide dismutase as well as EDTA was suppressing the toxic effect. In the same case the other group of investigators indicate that neuronal brain derived cells in culture may possess significant levels of endogenous xanthine [5]. It means that there is some natural level of $\mathrm{XO} / \mathrm{XDH}$ activity during the normal functional state as well as pathological conditions.

In our current experiments we have analyzed whether $\mathrm{XDH}$ might have any role in the development and growth of the human brain derived cells.

\section{Methods}

\subsection{Cell Culturing}

All procedures with the utility of biomaterials were carried out in accordance with the Declaration of Helsinki. 
Human embryos were obtained from elective abortions with the informed consent of the women seeking abortion. Moreover, as a biomaterial there were used only fetuses with the ages of formation not more than 12 weeks [10].

Brains of the human embryos (E90) were withdrawn, and placed in Neurobasal medium (NB, prenatal, Gibco Life Technologies) containing $0.05 \%$ bovine serum albumin (BSA). The tissue was isolated and incubated at $37^{\circ} \mathrm{C}$ for $20 \mathrm{~min}$ in $\mathrm{NB}$ containing $0.05 \%$ BSA, $0.15 \%$ Trypsine. Tissue was resuspended in fresh NB and mechanically disintegrated using a Pasteur pipette. The supernatant was discarded and the cell suspension resuspended in NB medium containing 1\% BSA. This procedure was repeated 3 times. Human brain cells were collected (1,000 rpm, $10 \mathrm{~min})$, washed and cultured at $37^{\circ} \mathrm{C}, 5 \% \mathrm{CO}_{2}$ in $35 \mathrm{~mm}$ Petri dishes pre-coated with poly-L-lysine (Sigma) containing $0.09 \% \mathrm{Na}_{2} \mathrm{HPO}_{4}, 1 \%$ glucose, $0.4 \% \mathrm{KCl}, 0.06 \% \mathrm{KH}_{2} \mathrm{PO}_{4}, 0.4 \% \mathrm{MgSO}_{4} \times 7 \mathrm{H}_{2} \mathrm{O}$ and $0.001 \%$ gentamicin sulfate. A day later the medium was replaced by NB containing 2\% B27-supplement (Gibco) and the cells' number was calculated on days second and $12^{\text {th }}[8]$.

\subsection{Cell Viability Evaluation}

It was prepared a cell suspension in BSS (Hank's Balanced Salt Solution, Product No. H9269, Sigma). After all it was transfer $0.5 \mathrm{ml}$ of $0.1 \%$ Trypan Blue solution to a test tube and added $0.3 \mathrm{ml}$ of BSS to $0.2 \mathrm{ml}$ of the cell suspension (dilution factor $=5$ ) and mixed thoroughly. We have allowed the cell suspension-Trypan Blue mixture to stand at least 5 minutes. Further it was transferred a small amount of the Trypan Blue-cell suspension mixture to both chambers of the hemacytometer. Nonviable cells stained blue. We have kept a separate count of viable and non-viable cells. Since $1 \mathrm{~cm}^{3}$ of the chamber is approximately $1 \mathrm{ml}$, the subsequent cell concentration $/ \mathrm{ml}$ (and total cell number) can be determined [11].

\subsection{Imaging Analysis}

It was used Polarizing microscope Biolar PI (PZO,Warsaw,Poland; magnification $1.25 \times 40$ or $1.25 \times 20$ ). The pictures were taken on $12^{\text {th }}$. Number of the cells were calculated by the utility of Pixcavator program IA 4.3 (Image analysis program, capturing contours of objects in the image and producing an Excel spreadsheet with the objects' locations and measurements).

\subsection{Statistics}

In our calculations we have used t-test (student) for pair comparison as well as ONE-WAY-ANOVA for the calculation of the significance of the comparable all groups. The results were considered statistically significant when p was lower or equal to 0.05 .

\section{Results}

To clarify the role of $\mathrm{XDH}$ in the processes of cells maturation and growth we have been treating the cell culture with the $\mathrm{NAD}^{+}$, xanthine, allopurinol, xanthine and $\mathrm{NAD}^{+}$, as well as the mixture consisting from $\mathrm{NAD}^{+}$, xanthine, allopurinol.
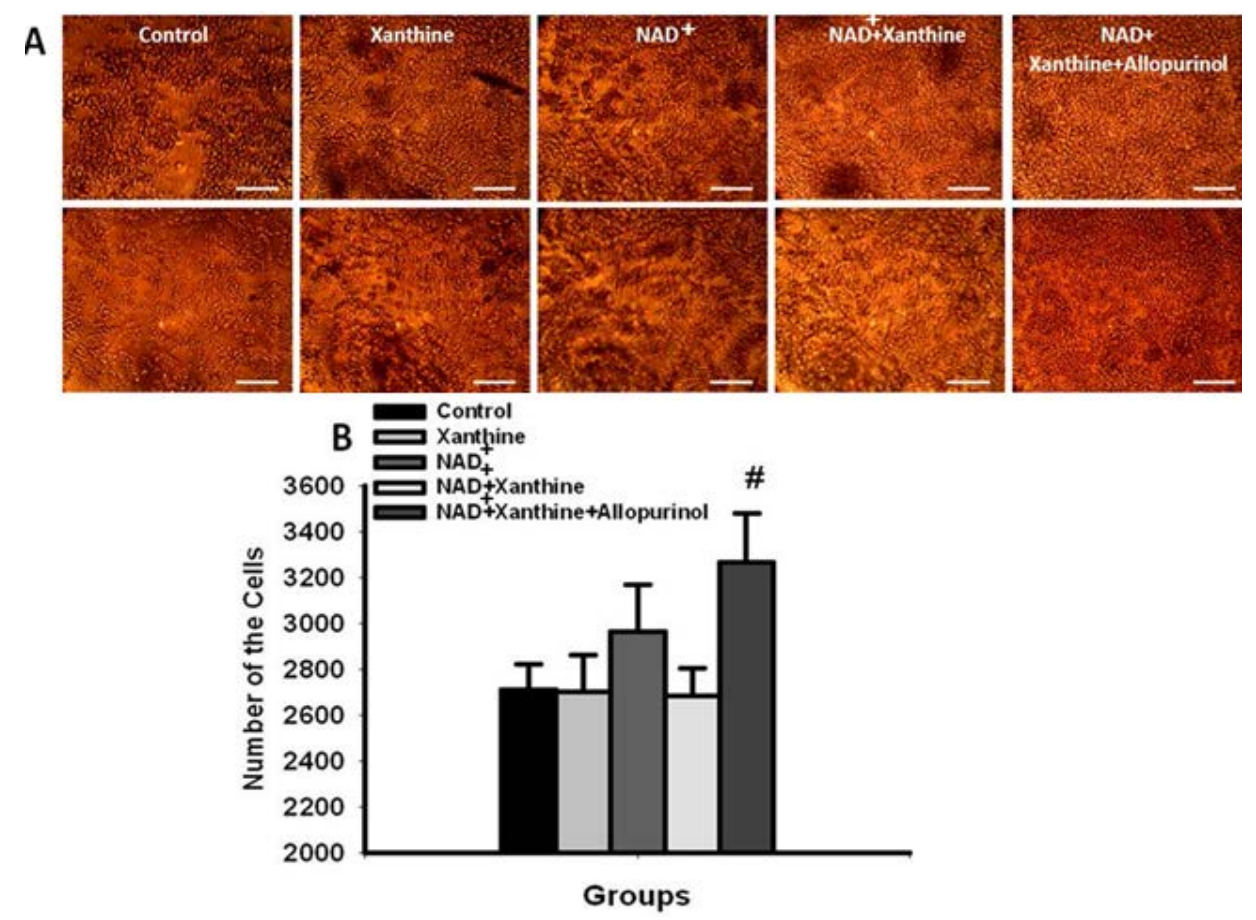

It has been used Polarizing microscope Bipolar PI (PZO,Warsaw,Poland; magnification 60x1.25x40). The cells were grown on the glass in the Petry dishes covered with the Poly-L-Lysine. The medium for cells served the Neurobasal/B27, containing xanthine, NAD ${ }^{+}, \mathrm{NAD}^{+}$and $x a n t h i n e, \mathrm{NAD}^{+}$, xanthine and allopurinol. The number of the cells in the field were counting by the utility of the Pixcavator programm, allowing authomatically to calculatate the size as well as the number of the cells. Also, it was used t-student test to calculate the significance of the results. $\mathrm{P}<0.05$ was considered significant.

Figure 1. Influnece of the exogenously added xanthine, $\mathrm{NAD}^{+}$and allopurinol on the growth and development of the human embryonic brain cells on the day $12^{\text {th }}$ 
1. NAD+, xanthine, and allopurinol increase the number and survival of human brain cells in the culture". During the first set of the experiment we have calculated the number of the cells in all five groups by the utility of Pixcavator program. The most effective treatment was performed by the simultaneous addition into the media $\mathrm{NAD}^{+}$, allopurinol and xanthine. In comparison with the

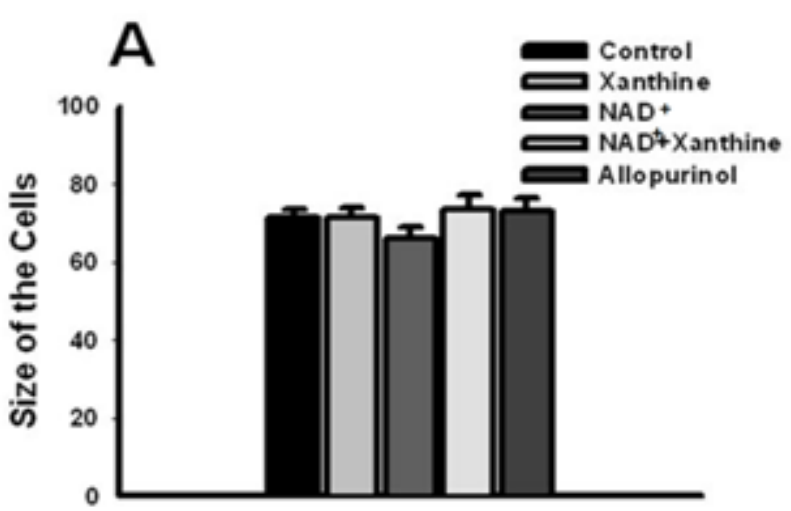

control group (2710,12 $\pm 110,68)$, exogenously xanthine $(2704,25 \pm 156,33)$ added as well as $\mathrm{NAD}^{+}$ $(2964,00 \pm 204,29)$, $\mathrm{NAD}^{+}$and xanthine of added groups $(2682,36 \pm 120,96)$ only the group treated with $\mathrm{NAD}^{+}$, xanthine and allopurinol $(3267,73 \pm$ 212,61, p < 0,05) promotes the elevation of the cells' number in the statistically significant way on the day $12^{\text {th }}$ (Figure 1$)$.

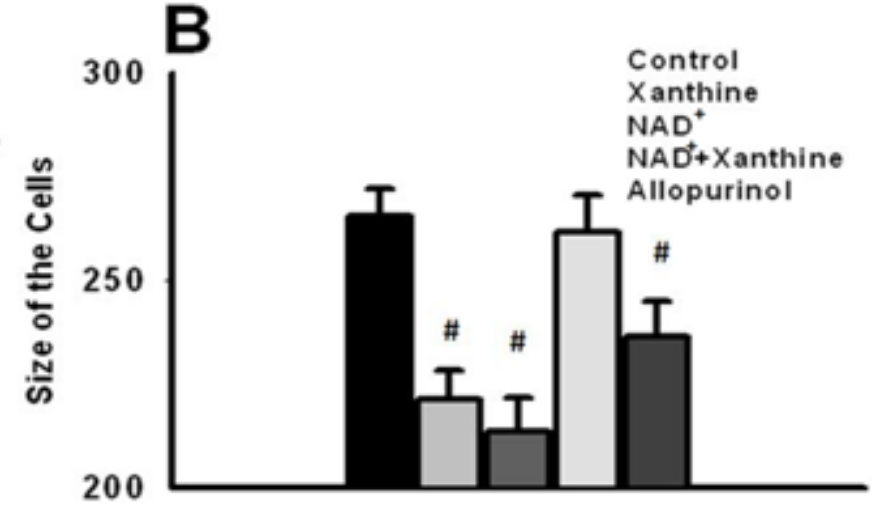

It has been used Polarizing microscope Bipolar PI (PZO,Warsaw,Poland; magnification 60x1.25x40). The cells were grown on the glass in the Petry dishes covered with the Poly-L-Lysine. The medium for cells served the Neurobasal/B27 containing xanthine, NAD+, NAD+ and xanthine, NAD+, xanthine and allopurinol. The number of the cells in the field were counting by the utility of the Pixcavator p as well as Imag Tool rogramm, allowing authomatically calculatate the size as well as the number of the cells. Results were calculated by the utility of SigmaStat 3.5. We have used one -wayANOVA for the comparison of the groups vs control or t-test for the coparison of two groups between each other. In the figures A there was no any statistically signifiicant difference netween the groups. In the figure B the statistically significant difference was noticed in the group comparison between control vs xanthine, NAD+, and allopurinol treated groups $(\mathrm{p}<0,05)$.

Figure 2. Measurement of the cells' (A) and embryonic bodies' sizes (B) on day $12^{\text {th }}$

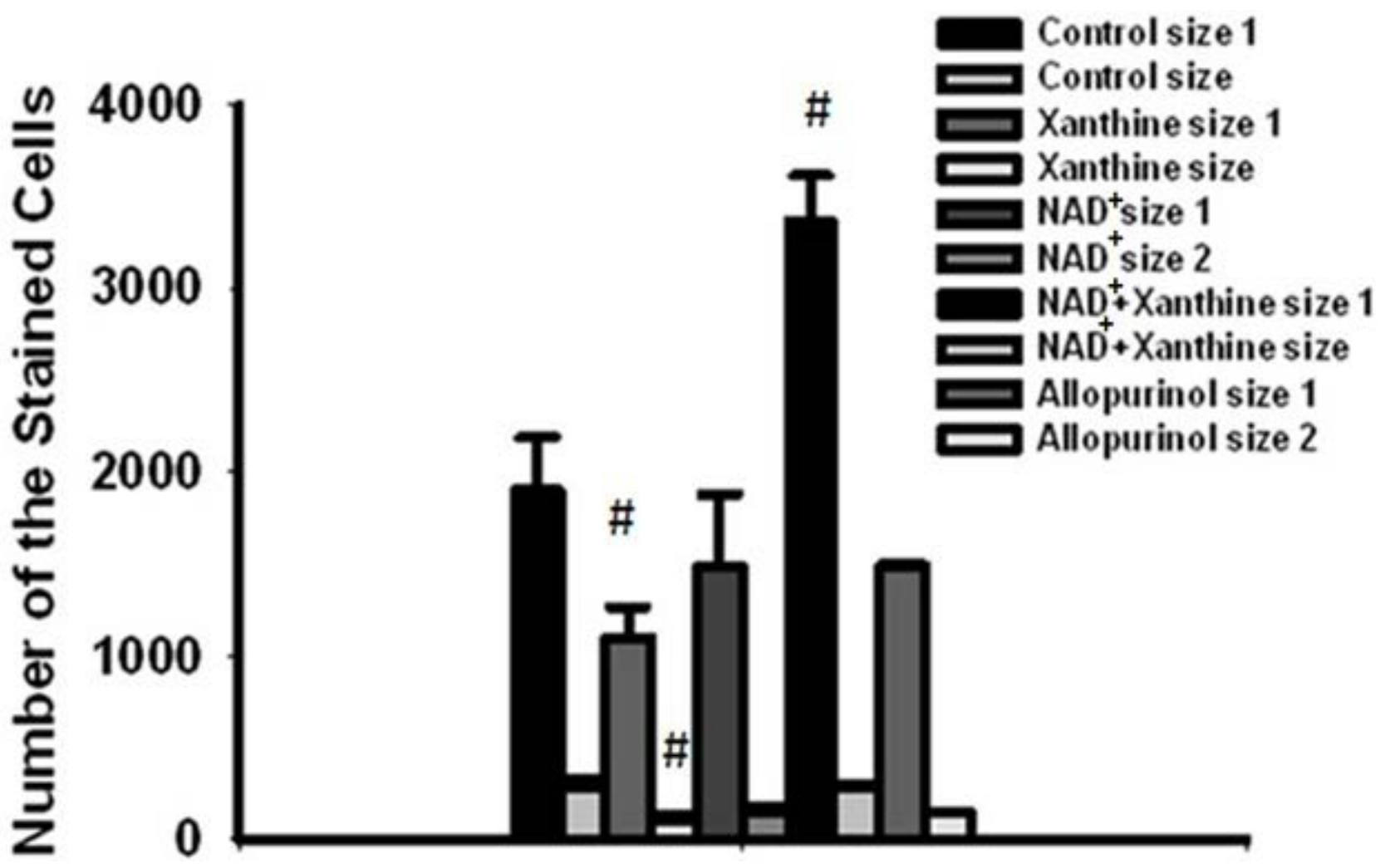

It has been used Polarizing microscope Bipolar PI (PZO,Warsaw,Poland; magnification 60x1.25x40). The cells were grown on the glass in the Petry dishes covered with the Poly-L-Lysine. The medium for cells served the Neurobasal/B27. The number of the cells in the field were counting by the utility of the Pixcavator programm. Results were calculated by the utility of SigmaStat 3.5. We have used one -way-ANOVA for the comparison of the groups vs control or the groups between each other.

Figure 3. Thrypan Blue staining of the human embryonic brain cells and cell bodies on the day $12^{\text {th }}$

2. NAD+, xanthine, and allopurinol increase bigger human brain cell death in culture. We have used Image Tool program to measure the size of the cells. The entire fraction of the cells were divided into the
2 groups: cells with the average cells size 70-80 microns2 and 200-300 microns2 cells groups, named embryonic bodies. It wasn't noticed any difference between the sizes of the cells in the groups (control 
group (71,36 $\pm 2,24)$, exogenously xanthine (71,35 \pm $2,60), \mathrm{NAD}^{+}(66,34 \pm 2,64), \mathrm{NAD}^{+}$and xanthine $(73,78 \pm 3,58) ; \mathrm{NAD}^{+}$, xanthine and allopurinol (73,24 \pm 3,28), (Figure 2A). Moreover, exogenous addition into the media above mentioned compounds promoted the decrease of the large cells groups' size $(265,49 \pm 6,76,221,52 \pm 6,73,213,64 \pm 8,0,261,84 \pm$ 8,80, 236,66 $\pm 8,22, \mathrm{p}<0,05$ between control and xanthine, $\mathrm{NAD}^{+}, \mathrm{NAD}^{+}$, xanthine and allopurinoltreated groups), (Figure 2B).

3. Detection of Cells Viability. Staining with Trypan Blue was helpful to determine the number of the single cells and cell bodies. Number of the death cells in comparison with the control groups in the cells groups treated with the xanthine, $\mathrm{NAD}^{+}$, as well as allopurinol group was less $(1900,89 \pm 285,58 ; 275,67$ \pm 50,85; 1096,50 \pm 167,68; 107,33 \pm 18,80, 1480,83 \pm 397,$67 ; 151,83 \pm 27,27 ; 1486,50 \pm 15,50 ; 150,00 \pm$ 4,00 ), whereas in the $\mathrm{NAD}^{+}$and xanthine treated group this number was elevated than in the control group in the statistically significant way $(3360,00 \pm$

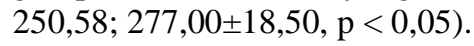

\section{Discussion}

The results, obtained from in vitro experiments have demonstrated that the inhibition of $\mathrm{XO} / \mathrm{XDH}$ activity promotes cells survival or/and proliferation. Our previous experiments were proving that the low concentration of allopurinol utilized from day first to 12 increased the cells number in the cell culture. The experiments were designed for the estimation of the endogenous XO activity [4]. Our current data demonstrate that even exogenous addition of xanthine, $\mathrm{NAD}^{+}$and allopurinol does promote increase of the cells' number.

The cells death detection with the trypan blue has shown almost the same results as during exogenous set of the experiments. Allopurinol treatment decreased the number of the death cells.

$\mathrm{XDH}$ activity in the group treated with the xanthine and $\mathrm{NAD}^{+}$increased the number of the death cells in the statistically significant way.

Also, the exogenously added xanthine as well as NAD ${ }^{+}$, which means exogenously promotion of $\mathrm{XO}$ and $\mathrm{XDH}$ activities decreased the size of the large cells fraction.

We have concluded that the treatment with the low concentration of allopurinol will guarantee the survival of the cells, decrease the number of the death cells and promote the proliferative processes.

These conclusions are similar for allopurinol treatment in condition of exogenously stimulated activity of $\mathrm{XO} / \mathrm{XDH}$ as well as endogenously measured activity of these enzymes.

\section{Abbreviation}

$\begin{array}{ll}\text { XOR } & \text { Xanthine Oxidoreductase } \\ \text { XO } & \text { Xanthine Oxidase } \\ \text { XDH } & \text { Xanthine Dehydrogenase }\end{array}$

\section{Acknowledgement}

The work was performed based on the ANSEF-2381 financing. I am thankful to S. Alaverdyan from Haybusak University, Department of Pharmacology, who was working with Pixcavator and Image Tool programs for measurement of the cells' size and calculation of their numbers. Prof Abrahamyan, director of the Institute of Perinatology, Obstetrics and Gynecology of Republican Maternity Hospital, was supportive and provided human embryonic brains (12 weeks old) for cell culturing. Academician A.A. Galoyan was consulting and directing the work.

\section{References}

[1] Al-Gonaiah, M., Smith, R.A. and Stone, T.W., Xanthine oxidaseinduced neuronal death via the oxidation of NADH: prevention by micromolar EDTA, Brain Res, 1280 (2009) 33-42.

[2] Ben-Schachar, D., Mitochondrial dysfunction in schizophrenia: a possible linkage to dopamine, J Neurochem, 83 (2002) 1241-1251.

[3] Berk, M., Copolov, D.L. and Dean, O., N-acetylcysteine for depressive symptoms in bipolar disorder-a double blind randomized placebo-controlled trial, Biol Psychiatry, 64 (2008) 468-475.

[4] Danielyan, K.E. and Kevorkian, G.A., Xanthine oxidase activity regulates human embryonic brain cells growth, Biopolym. Cell, 27(5) 350-353.

[5] Fatokun, A.A., Stone, T.W. and Smith, R.A., Hydrogen peroxide mediates damage by xanthine and xanthine oxidase in cerebellar granule neuronal cultures, Neurosci Lett, 416 (2007) 34-38.

[6] Harris, C.M. and Massey, V., The oxidative half-reaction of xanthine dehydrogenase with NAD; reaction kinetics and steadystate mechanism, J Biol Chem, 272(45) (1997) 28335-41.

[7] Ichikawa, M., Nishino, T., Nishino, T. and Ichikawa, A., Subcellular localization of xanthine oxidase in rat hepatocytes: high-resolution immunoelectron microscopic study combined with biochemical analysis, J Histochem Cytochem, 40(8) (1992) 1097103.

[8] Mattson, M.P. and Ruchlik, B., Cell culture of cryopreserved human fetal cerebral cortical and hippocampal neurons: neuronal development and resposes to trophic factors, Brain Research, 552 (1990) 2004-2212.

[9] Nierenberg, A.A., Ostacher, M.J., Calabrese, J.R., Ketter, T.A., Marangell, L.B., Miklowitz, D.J., Miyahara, S., Bauer, M.S., Thase, M.E., Wisniewski, S.R. and Sachs, G.S., Treatmentresistant bipolar depression: a STEPBD equipoise randomized effectiveness trial of antidepressant augmentation with lamotrigine, inositol, or risperidone, Am J Psychiatry, 163 (2006) 210-216.

[10] Rahman, A., Katzive, L., Stanley, K. and Henshaw, S.K., A Global Review of Laws on Induced Abortion, International Family Planning Perspectives1985-1997, 24 (1998).

[11] Tennant, J., Evaluation of the Trypan Blue technique for determination of cell viability, Transplantation, 2 (1964) 685-694. 